\title{
Retrospective host specificity testing of Cotesia urabae to assess the risk posed to the New Zealand nolid moth Celama parvitis
}

\author{
G.A. Avila ${ }^{1,3}$, T.M. Withers ${ }^{2,3}$ and G.I. Holwell ${ }^{1}$ \\ ${ }^{1}$ School of Biological Sciences, The University of Auckland, Private Bag 92019, Auckland 1142, \\ New Zealand \\ ${ }^{2}$ Scion, Private Bag 3020, Rotorua 3046, New Zealand \\ ${ }^{3}$ Better Border Biosecurity, New Zealand; www.b3nz.org \\ Correspondingauthor:g.avila@auckland.ac.nz
}

Additional retrospective testing of the gum leaf skeletoniser (Uraba lugens) biological control agent Cotesia urabae was conducted against the endemic moth Celama parvitis. Although this native was included in host specificity testing before EPA approved the parasitoid's release, this work aimed to increase the sample size to better assess the potential risk posed. The effect that different periods of host deprivation and prior oviposition experience had on the parasitoid's readiness to attack, was examined in a sequence of no-choice tests. No parasitoids emerged from the $52 \%$ of larvae that survived to pupation, thus, confirming C. parvitis as a non-host. Dissections of larvae that died during laboratory rearing revealed that $63 \%$ had contained a parasitoid, but no C. urabae parasitoid larvae developed beyond the second instar. Significant differences were found in the attack times according to the parasitoid's deprivation levels (age), and it was also observed that the duration until first attack significantly decreased after each non-target presentation.

\section{Novel release method proves successful: the gum leaf skeletoniser parasitoid Cotesia urabae establishes in two new locations}

\author{
B.A. Gresham ${ }^{1}$, T.M. Withers ${ }^{1}$, G.A. Avila² and L.A. Berndt ${ }^{1}$ \\ ${ }^{1}$ Scion, Private Bag 3020, Rotorua 3046, New Zealand \\ ${ }^{2}$ The University of Auckland, Private Bag 92019, Auckland 1142, New Zealand \\ Corresponding author: belinda.gresham@scionresearch.com
}

The Australian braconid wasp Cotesia urabae was first released in New Zealand in 2011, as a biological control agent for the gum leaf skeletoniser Uraba lugens (Lepidoptera: Nolidae). The larvae of this moth predominantly attack Eucalyptus spp. (Class: Symphyomyrtus) and, since its predicted future geographic range is extensive, there is concern it could become a serious pest of eucalypt plantations in New Zealand. Initial releases of C. urabae using adult parasitoids were made in Auckland at three separate sites between January and June 2011. Cotesia urabae established at each site and preliminary monitoring has revealed that the wasps have naturally dispersed to six other sites, ranging up to $6 \mathrm{~km}$ from an initial release site. In January 2012, C. urabae were released in Whangarei and Tauranga, trialling a novel method using parasitoid-attacked host larvae, rather than adult parasitoids. This method proved to be successful, with establishment now confirmed in both of these locations, and also provided greater flexibility. The two latest releases were made using the same method in Nelson (October 2013) and Napier (February 2014), but it is not yet known if the parasitoid has successfully established in these locations. 